\title{
Book Review: Kong, Kenneth. (2014). Professional Discourse. Cambridge: Cambridge University Press, pp 288.
}

\author{
Ruth Breeze ${ }^{1}$ \\ Instituto de Idiomas / Instituto Cultura y Sociedad
}

For readers of Revista de Lenguas para Fines Especificos, it is hardly necessary to state that language has a key role in configuring professional identities, shaping professional communication and facilitating professional activity. However, it is probably fair to say that as we advance in our knowledge of the professional area/s in which we specialise, the more we become aware of the immense complexity of language use in each different professional field. Above all, we have to grapple with the increasing specificity of the way that language is used by practitioners in a multitude of spoken and written genres, all of which are influenced by a range of power relations, social pressures, technical affordances and ideological trends, as well as being shaped by highly context-bound factors and the inevitable private intentions arising from human agency. In his book Professional Discourse, Kenneth Kong makes the courageous decision to stand back from this vast panorama in order to explore some general factors that can help us to understand the workings of discourse across professional contexts.

This book thus sets out from the premise that professional domains (business, law, medicine) should not be separated, but rather that professional discourse can be examined transversally, since the different professions "all draw on similar linguistic resouces to realize their practices" (p. 26). In one sense, this approach is productive, because it opens the door to understanding how members of different professional groups might interact, and how the boundaries of professions are negotiated. For example, it leads to a fruitful consideration of the nature of the profession as a

Corresponding author - Instituto de Idiomas / Instituto Cultura y Sociedad, Navarra (Spain). Email: rbreeze@unav.es 
"symbolic community" (p. 35) which moves on from Swales's (still extremely influential) concept of the "discourse community" to bring out the key role of language in constituting the ideological, social, cognitive and logistic (material) dimensions of the profession in question and the habitus of its members. Usefully for readers from areas other than applied linguistics, the different chapters include swift categorisations of many of the language features that are often analysed in this context (pronoun use, passivisation, nominalisation, etc.), and rapid overviews of the theoretical frameworks that can be used to understand real samples of language use (metadiscourse, speech act theory, politeness theory, intertextuality, genre theory). Case studies from law, medicine and business are provided to illustrate the application of these different approaches in various written professional genres, yielding some thought-provoking comparisons.

The main problem with the book is that when this cross-professional approach is taken further, some issues arise that call into question the validity of proceeding in this way. For example, after identifying passivisation and nominalisation as phenomena that seem to cut across the discourses of different professions, Kong examines texts from law and medicine, and reaches the (unsurprising) conclusion that "the passive voice and nominalisation have very different functions in the legal and medical professions, although they are characteristic of both" (p. 74). Such a line of inquiry is useful, perhaps, and sheds light on the discourses of law and medicine in particular, but its implications for our understanding of the abstract concept of "professional discourse" are harder to dilucidate. Along similar lines, although the chapter on "communicative competence" in the professions is interesting, and certainly sketches out the parameters for an enhanced understanding of what is this idea might entail, the truly interesting question of how people acquire professional communicative competence - and how we can guide our students as they transition from membership of the student community to that of the target legal, medical or other community - remains unanswered. In this sense, the book marks out a route map that could be used to guide future empirical work, rather than providing a comprehensive overview of the research that has already been carried out in this interesting and important field.

Among Kong's conclusions, the following are likely to resonate with the present readership: the need to focus on emerging professions, to expand the scope of analysis to involve the practitioners, the increasing pressure to understand how cultures intersect with professions, and most importantly, the need to gain deeper insights into the values, dispositions and identities that participants in the professional world acquire and enact. At the same time, Kong highlights the fact that professions as we know them are currently changing in consonance with trends in the global economy and ideological changes that are generating new systems of 
assessment, regulation and communication. Future research will surely address these phenomena in their different, context-bound empirical manifestations, and ultimately shed further light on the elusive notion of professional discourse in the abstract. 